\title{
Lung cancer transition rate by stages using discrete time markov model
}

\author{
Muhammad Hakeem Omar, Syazreen Niza Shair, Nurin Haniah Asmuni \\ Centre of Actuarial Studies, Faculty of Computer and Mathematical Sciences, Universiti Teknologi MARA, Malaysia
}

\begin{tabular}{l}
\hline \hline Article Info \\
\hline Article history: \\
Received Oct 10, 2019 \\
Revised Dec 11, 2019 \\
Accepted Dec 25, 2019 \\
\hline
\end{tabular}

\section{Keywords:}

Cancer transition rate

Functional markov model

Lung cancer

Markov model

Morbidity risk

\begin{abstract}
Morbidity risk is linked to the health status or a disease within a population. Morbidity risk is the risk of illness associated with health status or disease within a population. Cancer is one of the prime causes of both morbidity and mortality in majority of countries worldwide. In year 2016, the probability of Malaysian diagnosed with cancer before they reach age 75 is one over four. It has been reported that lung cancer has the highest deaths and it increased by $16.03 \%$ from 2012 to 2016. Malaysian National Cancer Registry reported that in year 2007 until 2011, 69.9\% of lung cancer are men and the remaining $30.1 \%$ are women. Chinese become the dominant lung cancer cases representing $51.04 \%$ of total lung cancer patients in Malaysia followed by Malay, $44.81 \%$ and Indian, $4.16 \%$. Treatments for lung cancer patients may vary by cancer stages. If cancer were just spread in one place, doctor may recommend a local treatment to get rid of cancer completely. Whereas, if a cancer has spread throughout the whole body, more comprehensive treatments may be needed. Therefore, knowing the probability of transition rate between cancer stages is important for healthcare cost effectiveness evaluation and expected cost calculation. This paper aims to estimate lung cancer transition rate by stages using the Functional Markov model. The Lung cancer transition rate will be calculated based on discrete time on a yearly basis. As a result, the probability of a Lung cancer patient recovering or deteriorating can be estimated.
\end{abstract}

Copyright $(2020$ Institute of Advanced Engineering and Science. All rights reserved.

\section{Corresponding Author:}

Muhammad Hakeem Omar,

Faculty of Computer and Mathematical Science,

Universiti Teknologi MARA (UiTM),

40450 Shah Alam, Selangor Darul Ehsan, Malaysia.

Email: hakeem_omar93@yahoo.com

\section{INTRODUCTION}

Nowadays, it has been recorded that cancer is the second leading cause of death worldwide [1]. Lung cancer is the most common type of cancer worldwide among men and the fourth most commonly occurring cancer among women [2]. Statistics by Roser and Ritchie [3] showed that in 2016, the number of lung cancer has reached 2,835,957 cases worldwide and the number of death from this cancer is equivalent to $1,706,879$ which is $60.18 \%$ from the total lung cancer cases.

While in Malaysia the number of lung cancer keep increasing from 2,804 cases in year 2000 to 5,303, 2016 with the total number of deaths 2,802 and 4,972, respectively [3, 4]. Malaysia National Cancer Registry report has listed the top 10 types of cancer in Malaysia and has positioned lung cancer as the top three highest number of occurrence cancer in Malaysia from 2007 to 2011 with a total of 10,608 lung cancer cases [5].

Lung cancer can be described as an abnormal cell that has growth abnormally lining the air passages inside the lungs tissue of one or both lungs. There are two types of lung cancer described by [6-9]: 
a) Non-Small Cell Lung Cancer: which are determined by the types of cells and the locations of the tumour. It mainly can be found on the cells that line the tubes into the lungs and smaller airways. It can also be classified as squamous cell carcinoma, adenocarcinoma or large cell carcinoma. The most common cases which is between $75 \%-85 \%$ cases.

b) Small Cell Lung Cancer: Usually start in the middle of the lungs and usually it spread early. Approximate to $15 \%-20 \%$ cases are Small Cell Lung Cancer

If cancer were just spread in one place, doctor may recommend a local treatment such as surgery or radiotherapy where this could be a suitable method to get rid of cancer completely [10]. However, a local treatment only treats an area of the body. If a cancer has spread throughout the whole body another treatment may be needed, such as chemotherapy, hormone therapy and targeted cancer drugs where it is called as systemic treatments [11]. Therefore, knowing the probability of transition rate between cancer stages is important so that we know which treatments are needed or suitable to use for each stage.

Cancer staging includes Number System and Tumour Nodes Metastasis (TNM). Such decision is crucial in determining the appropriate treatment and related cost through cost effectiveness evaluation in healthcare industry. Most cancer have 4 stages where often treatment team write the number stage in Roman numeral (I, II, III and IV) [11, 12]. In this research we adopt stages of cancer by Number System:

a) Stage I: Usually within a part of an organ where the cancer started, and the cancer are relatively small.

b) Stage II: Where the tumour is larger than stage 1 and the cancer has not spread into surrounding tissues or cancer starting to spread into lymph nodes where it close to the tumour, this stage is depending on the types of cancer.

c) Stage III: Where the tumour is larger than stage II and the cancer has spread into surrounding tissues and there is cancer in lymph nodes in the tumour area.

d) Stage IV: Where the cancer has spread to other part of body organ, is also called as metastatic cancer.

There are many journals in the literature used Markov model to estimate transition rates for illnesses by using longitudinal data which is difficult to access. For example, Gupta et al [13] use Markov model to explain cancer cells transition between states. Research from Jackson et al [14] also used Multiple Markov models to estimate the rates of transition between stages of specify type of disease. Duffy et al [15] estimated mean of sojourn time in breast cancer by using Markov chain model. Another research by Ritoe et al [16] used Markov model to study the impact of variations in the transition rates on life expectancy for laryngeal cancer. However, as far as we know, up to today, this is the first study that apply the Functional Markov model to estimate transition rates for illness. Leung [17] and Rickayzen [18] used the Functional Markov model to estimate transition rate for physical disability. Leung [17] stated that the Functional Markov model is suitable for cross sectional data given that longitudinal data is unavailable and Rickayzen [18] also mentioned that this method is proposed to overcome data scarcity in which longitudinal data for patients is difficult to access. Therefore, due to limitation data of lung cancer patient in Malaysia, this paper proposed the Functional Markov model to estimate lung cancer transition rates by stages to overcome data scarcity.

In medical sector publicly available, the estimation of cancer diagnosis rate is crucial to plan efficiently possible treatment in ensuring optimal cost and benefit allocation of related procedure or treatment. This paper aims to estimate lung cancer transition rate by stages using the Functional Markov Model. On the other hand, this model can also be applied in estimating the risk premium of cancer disease related insurance in the insurance industry. The Lung cancer transition rate will be calculated based on discrete time on yearly basis. By identifying the transition rate as objective, the probability of Lung cancer patient recovering or deteriorating can be estimated.

\section{METHODOLOGY}

\subsection{Data Collection}

Data are taken from Malaysian National Cancer Registry Report from year 2007 until 2011 [5]. This data is cross sectional data segregated by age, gender and stage of cancer. We focus on collecting data for lung cancer only. Retrospective study is designed and set in discrete time.

\subsection{Description Analysis}

From the collected data, descriptive analysis will be performed to analyses the number of lung cancer cases and prevalence rate patterns in Malaysia. Data will be analyzed according to different lung cancer stages, gender, age groups and ethnicities. These will provide detail information on the pattern of lung cancer prevalence rates which will eventually necessary to develop the model. 


\subsection{Independent T-Test}

Independence T-test is used to determine whether or not the difference between the two observed means exceeds the difference that would expect by chance $[19,20]$. The hypothesis is to determine whether there is a difference between male and female means. Thus, the null and alternative hypotheses that will be tested are:

$$
H_{0}: \bar{X}_{m}-\bar{X}_{f}=0, \quad H_{1}: \bar{X}_{m}-\bar{X}_{f} \neq 0
$$

Where the significant level is $\alpha=0.05$ or $5 \%$. Follow the Critical value which is:

$$
t=\frac{\left(\bar{X}_{m}-\bar{X}_{f}\right)-\left(\mu_{m}-\mu_{f}\right)}{\sqrt{\frac{\left(S_{m}\right)^{2}}{n_{m}}+\frac{\left(S_{f}\right)^{2}}{n_{f}}}}
$$

Where, $\mathrm{m}$ is referring to Male and $\mathrm{f}$ referring to Female. $\bar{X}$ is Sample meanwhile $\mu$ is Population mean. Parameter $\mathrm{S}$ is used as sample standard deviation and parameter $\mathrm{n}$ as a symbol number of sample size. Decision rules for this test are, reject $H_{0}$ if $|t|>t_{a, v=n_{m}+n_{f}-2}$ or p-value $<\alpha[19,20]$.

\subsection{ANOVA Test}

The ANOVA test is conducted to determine if the prevalence rate of cancer differs according to type of cancer. We compare the mean of prevalence rates for ten cancer types ranked as the top recorded cases by the Malaysian National Cancer Registry Report. The mean of prevalence rate for each cancer type is calculated from the recorded cases from year 2007 to 2011. Thus, the hypothesis that will be tested is as follows:

$$
H_{0}: \mu_{1}=\mu_{2}=\mu_{3}=\cdots=\mu_{10} \quad H_{1}: \text { At least one of the means are not equal }
$$

Where the significant level is $\alpha=0.05$ or $5 \%$. Follow the Critical value which is:

$$
F=\frac{M S T R}{M S E}=\frac{\left(\frac{S S T R}{d f_{T R}}\right)}{\left(\frac{S S E}{d f_{E}}\right)}
$$

Where, MSTR is mean square for treatment and MSE is mean square for error. Decision rules for this test are, reject $H_{0}$ if $F>F_{a, v_{1}=n_{1}-1, v_{2}=n_{2}-1}$ or p-value $<\alpha[19,20]$.

\subsection{The Functional Markov Model}

Steven Haberman from University of London [21] and researches from London [22], Pitacco [23], Sonnenberg and Beck [24], Mohagheghi [25], Jackson [26], Shair [27], Asmuni [28] and Samsuddin and Ismail [29] has agreed that the Multiple State Markov model is the best method to describe and estimate the process of an individual's movement through a series of states, where the timing of events and repeatable events are important. Transition diagram for lung cancer Figure 1.

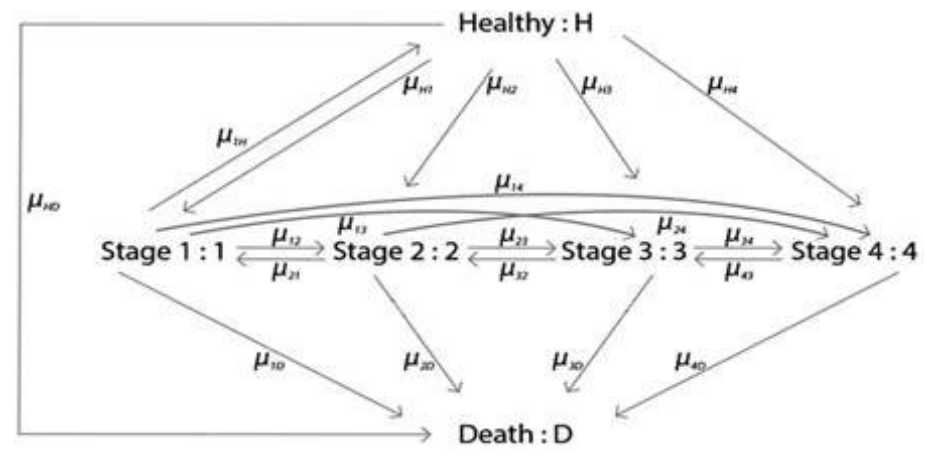

Figure 1. Transition diagram for lung cancer 
$\mu_{i j}$, the transition probabilities move form lung cancer state $\mathrm{i}$ to state $\mathrm{j}$, where:
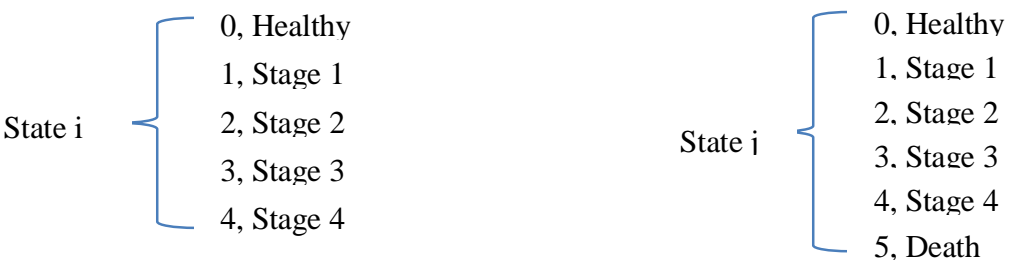

\subsubsection{Additional Mortality}

The mortality rate is higher at severe stages, which are stage III and IV. An additional mortality for late cancer stages should be included when fit the model. An assumption has been made for additional mortality based on Rickayzen assumption [18]:

a) There is no extra mortality for healthy stage, stage I and stage II. This is because tumour cancer has not spreading into surrounding tissues [11].

b) The extra mortality increases linearly starting from stage III onwards. This is because in stage III and IV tumour cancer has spread into surrounding tissues [11].

c) Based on survival time of lung cancer patients defined by [30], the maximum extra mortality is 0.5202 .

d) The choice of the pivotal age is 42 for lung cancer patients describe by Figure 2(a) and the steepness factor is 1.1 .

e) Model is same for male and female.

$$
\operatorname{AddMort}(n)=\left(\frac{0.5202}{1+1.1^{42}}\right)\left(\frac{\operatorname{Max}((n-2), 0)}{2}\right)
$$

Where, $\mathrm{n}$ referring to number of stages ( $\mathrm{n}=0$ means healthy stage) and note that, the extra mortality might change with time [18]

\subsubsection{Probability of Becoming Diagnosed}

The formula used to estimate the probability of people becoming diagnosed are same for male and female in lung cancer. If there is a different in the probability of becoming diagnosed between male and female, an extra parameter E will be used to give a "kink" in the NewDiagnosed function [17, 18].

$$
\text { NewDiagnosed }=A+\frac{D-A}{1+B^{C}}
$$

Where parameter $\mathrm{A}$ is the limit of the probability of becoming diagnosed at early stage. $\mathrm{B}$ and $\mathrm{C}$ is to determine how rapidly the probabilities change between the two extreme values. Lastly, D is the limit or probability of becoming diagnosed that would apply at higher stage $[17,18]$.

\subsubsection{Severity of New Diagnosed}

$$
\begin{aligned}
& \operatorname{Severity}(\mathrm{n})=\frac{W(n) \cdot f(0)^{n-1}}{\operatorname{Scale}(0)} \\
& \mathrm{f}(0)=A+\frac{1-A}{1+B^{C}}
\end{aligned}
$$

Where $\mathrm{W}(\mathrm{n})$ is the widths. Scale is to ensure that the probabilities up to 1 and its inclusion means that we can arbitrarily set $\mathrm{W}(1)=1$. The three parameters $(\mathrm{A}, \mathrm{B}, \mathrm{C})$ is relating to age dependence (they are distinct from the parameters used in formulae for NewDiagnosed) [17, 18]

\subsubsection{Deterioration from Diagnosed States}

The probability of someone in diagnosed category $m$ deteriorating to category $n$ is $\mathrm{F}^{\mathrm{m}}$ times the probability that a healthy person deteriorates to category $n[17,18]$

Deteriorate $(\mathrm{m}, \mathrm{n})=\operatorname{Deteriorate}(0, \mathrm{n}) \times F^{m}$

Deteriorate $(0, \mathrm{n})=\operatorname{NewDiagnosed} \times \operatorname{Severity}(n)$ 


\subsubsection{Improvement}

In year 2010 and 2011, 2151 and 2077 total lung cancer has been recorded respectively throughout the year [5]. The diagnosis rate of cancer in 2010 is 7.65146 per 100,000 population while in 2011, the rate is 7.25333 per 100,000 population. Therefore, the estimated improvement rate from 2010 to 2011 is $5.2 \%$. Due to lack of publicly available data on cancer recovery rate, this rate is applied to all cancer stages.

\section{RESULTS AND ANALYSIS}

\subsection{Analysis of Malaysian Lung Cancer Patient Data}

As shown in the Figure 2, male is consistently higher compared to female for all lung cancer stages in which the biggest gap occurred at Stage IV. In total lung cancer cases recorded by Malaysia Cancer Statistics, Figure 2 [5] shows that male has 7,415 cases from year 2007 until 2011 while female total cases are half from Male cases which is 3,193 cases. In other words, male contributed a $69.9 \%$ cases and dominant compared to female which is only $30.1 \%$ cases.

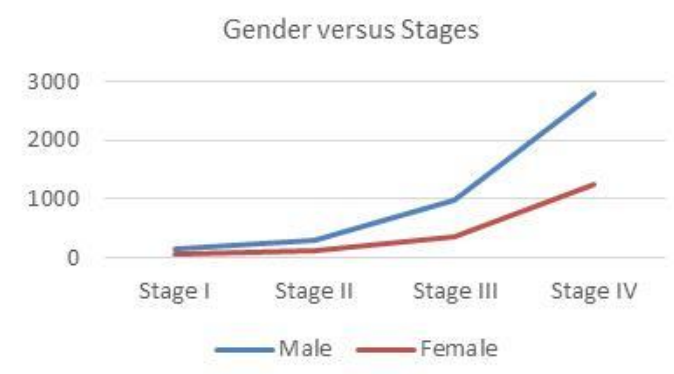

Figure 2. Number of lung cancer patients by stage and gender

From Figure 3a, the highest cases of lung cancer occurred between ages 65 and 69 from year 2007 until 2011, which is 1,267 total cases or of $17.087 \%$ of total male lung cancer patients. While for female, the highest cases are 514 cases with proportion of $16.0977 \%$ on age 75 and above. The figure also shows that the starting ages of Malaysia patients have lung cancer between ages 20 to 24 for both genders. This descriptive statistics finding is supported by White et all [31], where cancer development is a complex process that occurs over a span of many years. This is because cells will be damaged over time and will build up as we age, therefor the process of buildup cells can sometimes lead to cancer.

From Figure 3b, it is shown that Chinese has dominant Lung cancer cases with $51.04 \%$ of total Lung cancer patients in Malaysia follow by Malay, $44.81 \%$ and Indian, 4.16\%. Malaysia Cancer Statistics, Data and Figure [5] also stated the lifetime risk male and female for each ethnic. Lifetime risk for males to get lung cancer was 1 in 55, while for females was 1 in 135. Males lifetime risk for Chinese was 1 in 43 followed by Malay and Indian, 1 in 62 and 1 in 103 respectively. On other hand, the lifetime risk for females Chinese, Malay and Indian was 1 in 97, 1 in 185 and 1 in 255 accordingly.

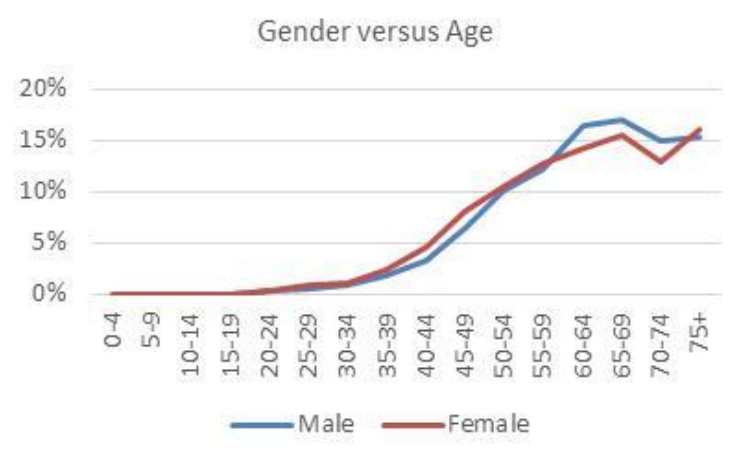

(a)

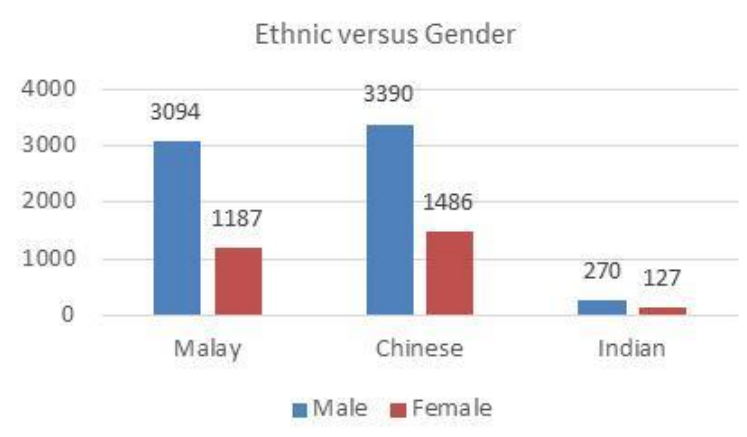

(b)

Figure 3. Proportion of lung cancer patients by age and gender (a) and number of lung cancer patients by ethnic and gender (b) 


\subsection{Independent T-TEST}

Table 1 shows the mean of diagnosis prevalence rate, standard deviation and standard error mean for male and female by using 30 sample of data collected from several states in Malaysia as found in [5]:

Levene test is used to check the equality of variance by checking on the significant value, if the value more than 0.05 , equal variance is assumed $[19,20]$. Table 2 shows that the significant more than 0.05 , therefor equal variance is assumed. Thus, the independent T-test assumption is fulfilled where the data has homogeneity of variance.

In conclusion, T-test for equality of means can be check by the significant value on Table 3. If the significant value more than 0.05 therefor equality of means is assumed [19, 20]. Results shows, t-test for equality of means are less than 0.05 , which is means the prevalence rate of cancer for male and female is significantly difference from each other. Its shows that gender is one of the risk factors determining the transition of lung cancer disease.

Table 1. Descriptive Statistics

\begin{tabular}{ccccc}
\hline Gender & $\mathrm{N}$ & Mean & Std. Deviation & Std. Error Mean \\
\hline Male & 15 & 0.7178 & 0.05657 & 0.01461 \\
Female & 15 & 0.2822 & 0.05657 & 0.01461 \\
\hline
\end{tabular}

Table 2. Levene Test for Equality of Variences

\begin{tabular}{cc}
\hline $\mathrm{F}$ & Sig. \\
\hline 0.000 & 1.000 \\
\hline
\end{tabular}

Table 3. T-test for equality of means

\begin{tabular}{|c|c|c|c|c|c|}
\hline \multirow[b]{2}{*}{$\mathrm{T}$} & \multirow{2}{*}{ df } & \multirow{2}{*}{ Sig. (2-tailed) } & \multirow[b]{2}{*}{ Mean Difference } & \multirow{2}{*}{ Std. Error Difference } & $95 \%$ Confidence interval of the \\
\hline & & & & & Lower $\quad$ Upper \\
\hline 21.091 & 28 & 0.000 & 0.43563 & 0.02065 & 0.39332 \\
\hline
\end{tabular}

\subsection{ANOVA Test}

In conclusion, this table prove that means for each type of cancer are different to each other since the significant value is less than 0.05 . Therefor the assumption of each type of cancer are different to each other has been prove. Test of homogeneity variance as shown in Table 4.

The significant value for homogeneity is 0.493 which is more than 0.05 . Thus, the data variance is homogeneity. ANOVA as shown in Table 5.

Table 4. Test of Homogeneity Variance

\begin{tabular}{cccc}
\hline Levene Statistic & df1 & df2 & Sig. \\
\hline 0.952 & 9 & 40 & .493 \\
\hline
\end{tabular}

Table 5. ANOVA Table

\begin{tabular}{lccccc}
\hline & Sum of Squares & df & Mean Square & F & Sig. \\
\hline Between Groups (TR) & 615.917 & 9 & 68.435 & 926.760 & 0.000 \\
Within Groups (E) & 2.954 & 40 & 0.074 & - & - \\
Total (T) & 618.870 & 49 & - & - & - \\
\hline
\end{tabular}

\subsection{The Functional Markov Model}

Additional mortality:

Table 6. New Mortality

\begin{tabular}{cccccc}
\hline & Healthy & Stage I & Stage II & Stage III & Stage IV \\
\hline Mortality & 0.0047 & 0.0047 & 0.0047 & 0.0047 & 0.0047 \\
Additional Mortality & 0 & 0 & 0 & 0.004665 & 0.009329 \\
New Mortality & 0.0047 & 0.0047 & 0.0047 & 0.009365 & 0.014029 \\
\hline
\end{tabular}


Probability of becoming diagnosed:

Table 7. Parameter value for NewDis

\begin{tabular}{cccccc}
\hline Variable & $\mathrm{A}$ & $\mathrm{B}$ & $\mathrm{C}$ & $\mathrm{D}$ & NewDiagnosed \\
\hline Value & 0.00245 & 1.26653 & 91.78923 & 0.08457 & 73.56591 \\
\hline
\end{tabular}

Severity of new diagnosed:

Table 8. Parameter value for Severity

\begin{tabular}{cccccccc}
\hline Variable & $\mathrm{p}$ & $\mathrm{Q}$ & $\mathrm{r}$ & $\mathrm{W}(1)$ & $\mathrm{W}(2)$ & $\mathrm{W}(3)$ & $\mathrm{W}(4)$ \\
\hline Value & 0.9857 & 1.4268 & 74.5742 & 1 & 0.7563 & 0.9931 & 0.1540 \\
\hline
\end{tabular}

Transition probability:

Table 9. One-year Lung Cancer Transition Probabilities

\begin{tabular}{ccccccc}
\hline & Healthy & I & II & III & IV & DEAD \\
\hline Healthy & 0.992847 & 0.000858 & 0.000640 & 0.000828 & 0.000127 & 0.004700 \\
I & 0.050912 & 0.928084 & 0.006542 & 0.008468 & 0.001294 & 0.004700 \\
II & - & 0.046590 & 0.848897 & 0.086582 & 0.013231 & 0.004700 \\
III & - & - & 0.044544 & 0.810810 & 0.135281 & 0.009365 \\
IV & - & - & - & 0.051270 & 0.934700 & 0.014029 \\
\hline
\end{tabular}

Table 9 shows one-year lung cancer transition probabilities estimated using the Functional Markov Model. It shows that a person that in a healthy condition have a $0.0858 \%$ to chance cancer stage I and $0.064 \%$ chance to diagnose with cancer stage II. There is $93.47 \%$ chance a cancer patient at stage IV to stay in the same state with the chance to improve to Stage III is only $5.127 \%$. The probability for a cancer patient in stage I and stage IV to recover are higher compare to patient in stage II and stage III, where the probability to deteriorate are higher than recovery rate. The table also shown that mortality rate is starting to increase from stage III.

Based on [21], the summation transition rate for each stages must be equal to 1 . Hence, Table 9 proved the assumption of Markov Model is met where the total of transition rate for each stage should be equal to 1. Furthermore, by using Functional Markov Model the absolute different between data and model is only $6.70 \%$, where the error occurred in stage I by $4.24 \%$ and in stage IV by $1.97 \%$.

\section{CONCLUSION}

As far as we know, up to today, this is the first paper that used the Functional Markov model to estimate transition probabilities for illness by using cross sectional data which is a retrospective study design and set in discrete time. This study has estimated one-year Lung Cancer transition probabilities of Malaysia patients. It can conclude that this model suits well for all stages and both genders except for stage I, where the model under estimate the rate. The multi state model for lung cancer disease developed in this paper is very useful in the area of health economics to conduct the cost effectiveness healthcare analysis. The calculation of deterioration and improvement rate of cancer from each stage can be used to study the effectiveness of benefit allocation for patients, pre and post treatment. It can also be applied in the insurance sector to determine the accurate risk premium for cancer related insurance. Further studies may be done to improve the accuracy of deterioration rate for cancer stage $I$ in this model and to test the suitability and accuracy of Functional Markov model for modelling transition rate for other type of illnesses.

\section{ACKNOWLEDGEMENT}

This work is supported by the Institute of Quality and Knowledge Advancement (InQKA). This research has received funding support from Universiti Teknologi MARA through Lestari Grant with a grant number of 600-IRMI/DANA/5/3/LESTARI (0134/2016) 


\section{REFERENCES}

[1] M. A. Kahya, 'Classification enhancement of breast cancer histopathological image using penalized logistic regression', Indones. J. Electr. Eng. Comput. Sci. Inst. Adv. Eng. Sci., vol. 13, no. 1, pp. 405-410, 2019.

[2] B. W. Stewart and C. P. Wild, 'World Cancer Report 2014', Int. Agency Res. Cancer, World Heal. Organ., 2014.

[3] M. Roser and H. Ritchie, 'Cancer', Published online at OurWorldInData.org., 2018. [Online]. Available: https://ourworldindata.org/cancer.

[4] M. H. Omar, N. H. Asmuni, and S. N. Shima, 'Healthy life expectancy vs health expenditure by sullivan method in Malaysia', Indones. J. Electr. Eng. Comput. Sci. Inst. Adv. Eng. Sci., vol. 14, no. 1, pp. 402-406, 2019.

[5] A. M. Azizah, I. Nor Saleha, A. Noor Hashimah, Z. Asmah, and W. Mastulu, 'Malaysian National Cancer Registry Report 2007-2011', Energy Manag. (New Delhi), vol. 7, no. 1, pp. 45-51, 2016.

[6] L. Wuellner, 'Understanding Lung Cancer', 2014.

[7] P. Alder, Richard, 'Lung cancer', Magill's Med. Guid. (Online Ed., 2017.

[8] M. Onaitis and T. A. D'Amico, 'Lung Cancer', Sabist. Spencer's Surg. Chest, pp. 279-286, 2010.

[9] Boehringer Ingelheim, 'Lung cancer', Gan To Kagaku Ryoho., vol. 28, no. 2, pp. 163-167, 2001.

[10] World Health Organization, Cancers. 2010.

[11] American Joint Committee on Cancer, 'Purpose and Principal of Cancer Staging', AJCC Cancer Staging Man. 7th Ed., pp. 1-12, 2010.

[12] J. D. Brierley, M. K. Gospodarowicz, and C. Wittekind, 'TNM classification of malignant tumours - 8th edition', Union Int. Cancer Control, p. 272, 2017.

[13] P. B. Gupta et al., 'Stochastic state transitions give rise to phenotypic equilibrium in populations of cancer cells', Cell, vol. 146, no. 4, pp. 633-644, 2011.

[14] C. H. Jackson, L. D. Sharples, S. G. Thompson, and S. W. Duffy, ‘<1467-9884.00351.Pdf>’, pp. 193-209, 2003.

[15] S. W. Duffy, H. -H Chen, L. Tabar, and N. E. Day, 'Estimation of mean sojourn time in breast cancer screening using a Markov chain model of both entry to and exit from the preclinical detectable phase', Stat. Med., vol. 14, no. 14, pp. 1531-1543, 1995.

[16] S. C. Ritoe et al., 'Effect of routine follow-up after treatment for laryngeal cancer on life expectancy and mortality: Results of a Markov model analysis', Cancer, vol. 109, no. 2, pp. 239-247, 2007.

[17] Leung and Edward, 'Projecting the Needs and Costs of Long Term Care in Australia', 2003.

[18] B. D. Rickayzen, A Multi-State Model of Disability for the United Kingdom: Implications for Future Need for Long-Term Care for the Elderly, no. June 2002. 2002.

[19] N. Bachok, Basic Statistics Step by Step Guide Using PASW 18. Unit Biostatistik \& Methodologi Penyelidikan USM, 2011.

[20] M. H. Kutner, C. J. Nachtsheim, J. Neter, and W. Li, Applied Linear Statistical Models, Fifth. New York: McGrawHill Education, 2005.

[21] S. Haberman, 'HIV, AIDS, Markov processes, and Health and disability insurance', J. Actuar. Pract., vol. 3, no. 1, pp. 51-74, 1995.

[22] D. London, Survival Models And Their Estimation, Second. United State of America: ACTEX, 1997.

[23] E. Pitacco, Health Insurance. Basic Actuarial Models. 2014.

[24] F. Sonnenberg and J. Beck, 'Medical Decision Making Markov Models in Medical Decision Making: A Practical Guide Markov Models in Medical Decision Making: A Practical Guide', Med Decis Mak., vol. 13, pp. 322-338, 1993.

[25] M. Mohagheghi and K. Salehi, 'Improving graph-based methods for computing qualitative properties of markov decision processes', Indones. J. Electr. Eng. Comput. Sci. Inst. Adv. Eng. Sci., vol. 18, no. 1, pp. 1571-1577, 2020.

[26] C. Jackson, 'Multi-state modelling with R: the msm package', Cambridge, UK, pp. 1-53, 2007.

[27] S. N. Shair and A. Studies, 'Three essays on Malaysian population ageing', 2016.

[28] N. H. Asmuni, 'Essays on Annuities and their Economic Value for Retirees', 2015.

[29] S. Samsuddin and N. Ismail, 'Transition probabilities of health states for workers in Malaysia using a Markov chain model', AIP Conf. Proc., vol. 1830, 2017.

[30] S. H. Shieh, J. C. Probst, F. C. Sung, W. C. Tsai, Y. S. Li, and C. Y. Chen, 'Decreased survival among lung cancer patients with co-morbid tuberculosis and diabetes', BMC Cancer, vol. 12, pp. 1-8, 2012.

[31] M. C. White, D. M. Holman, J. E. Boehm, L. A. Peipins, M. Grossman, and S. Jane Henley, 'Age and cancer risk: A potentially modifiable relationship', Am. J. Prev. Med., vol. 46, no. 3 SUPPL. 1, pp. S7-S15, 2014. 